„Przekłady Literatur Słowiańskich”. T. 9, cz. 3 ISSN 2353-9763 (wersja elektroniczna)

DOI 10.31261/PLS.2019.09.03.18

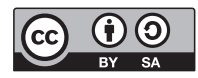

\title{
Bibliografia przekładów literatury polskiej w Słowacji w 2017 roku
}

\section{The Bibliography of Translations of Polish Literature in Slovakia in 2017}

\author{
Zuzana Obertová \\ iD https://orcid.org/0000-0002-5766-4081 \\ COMENIUS UNIVERSITY IN BRATISLAVA \\ zuzana.pojezdalova@gmail.com
}

Data zgłoszenia: 10.09 .2018 r. ～Data akceptacji: 29.10 .2018 r. 


\section{Publikacje książkowe}

1. Borowski Tadeusz: Pożegnanie z Marią / Nech sa páči do plynu.

Prel. Jozef G e r b ó c, Jozef M a r u š i a k. Bratislava, Artforum, 2017, 188 s. [proza].

2. Chmielewska Iwona: Dwoje ludzi / Dvaja ludia.

Prel. Lubomír F e ld e k. Prešov, OZ Slniečkovo, 2017, 32 s. [poezja].

3. Czechowicz Józef: Ballada z tamtej strony / Balada z tamtej strany. Prel. Juraj A n d r i čík. Bratislava, Drewo a srd, Vlna, 2017, 119 s. [poezja].

4. Czeska-Mączyńska Maria: Rycerz Chrystusowy / Kristov rytier. Prel. Števo S c hult z. Trnava, Spolok sv. Vojtecha, 2017, 191 s. [proza].

5. Dołęga-Mostowicz Tadeusz: Znachor / Mastičkár.

Prel. Olga H r d li č k o vá. Bratislava, Citadella Publishing, 2017, 252 s. [proza].

6. Górecki Wojciech: Planeta Kaukaz / Planéta Kaukaz.

Prel. Alexander H o r á k. Krásno nad Kysucou, Absynt, 2017, 240 s. [reportaż].

7. Hugo-Bader Jacek: Dzienniki kołymskie / Kolymské denníky. Prel. Patrik O r i e š e k. Krásno nad Kysucou, Absynt, 2017, 352 s. [reportaż].

8. Kapuściński Ryszard: Cesarz / Cisár. Prel. Patrik O r i e š e k. Žilina, Absynt, 2017, 152 s. [reportaż].

9. Kurtyka Wojciech: Chiński maharadża / Čínsky maharadža. Prel. Sylvia G a la j d a. [B.m.w.], MediaBusiness.sk, 2017, 96 s. [proza].

10. Moczarski Kazimierz: Rozmowy z katem / Rozhovory s katom. Prel. Milica N o vá k o vá. Krásno nad Kysucou, Absynt, 2017, 448 s. [reportaż].

11. Murek Weronika: Uprawa roślin południowych metoda Miczurina / Pestovanie teplomilných rastlín podla Mičurina. Prel. Patrik O r i e š e k. Bratislava, OZ Brak, 2017, 128 s. [proza].

12. Nurowska Maria: Imię twoje... / Tvoje meno ta predchádza. Prel. Ivana S c h é r o vá. Bratislava, Vydavatel'stvo spolku slovenských spisovatelov, 2017, $168 \mathrm{~s}$. [proza].

13. Przybyszewski Stanisław: Krzyk / Krik. Prel. Tomáš H o r vát h. Bratislava, Európa, 2017, 128 s. [proza].

14. Sapkowski Andrzej: Wiedźmin. Tom 5: Chrzest ognia / Zaklínač V: Krst ohňom.

Prel. Karol C h m e l. Praha, Nakladatel'stvo Plus v Albatros Media, 2017, 344 s. [proza]. 
15. Sapkowski Andrzej: Wiedźmin. Tom 6: Wieża jaskółki / Zaklínač VI: Veža lastovičky.

Prel. Karol C h m e l. Praha, Nakladatel'stvo Plus v Albatros Media, 2017, 448 s. [proza].

16. Sapkowski Andrzej: Wiedźmin. Tom 7: Pani Jeziora / Zaklínač VII: Pani jazera.

Prel. Karol C h m e l. Praha, Nakladatel'stvo Plus v Albatros Media, 2017, 576 s. [proza].

17. Stasiuk Andrzej: Wschód / Východ.

Prel. Tomáš H o r vát h. Bratislava, Slovart, 2017, 216 s. [proza].

18. Szabłowski Witold: Tańczące niedźwiedzie / Tancujúce medvede.

Prel. Karol C h m el. Krásno nad Kysucou, Absynt, 2017, 232 s.

[reportaż].

19. Szabłowski Witold: Zabójca z miasta moreli / Vrah z mesta marhúl.

Prel. Juraj Ko u d e la. Krásno nad Kysucou, Absynt, 2017, 260 s.

[reportaż].

20. Szpilman Władysław: Pianista / Pianista.

Prel. Alexander H o r á k. Bratislava, Premedia, 2017, 240 s. [proza].

21. Świderska-Pelinko Marta: Tam gdzie łkaja skrzypce / Tam, kde plačú husle.

Prel. Radovan B r e n ku s. Košice, Pectus, 2017, 336 s. [proza].

22. Tochman Wojciech: Eli, Eli / Eli, Eli.

Prel. Slavomír B a ch u r a. Žilina, Absynt, 2017, 144 s. [reportaż].

23. Wotowski Stanisław Antoni: Upiorny dom / Dom prízrakov.

Prel. Tomáš H o r vá th. Bratislava, Európa, 2017, 160 s. [proza].

\section{Publikacje w czasopismach}

1. „Literárny týždenník” 2017, nr 43-44.

Iwaszkiewicz Jarosław

Borsuk / Jazvec.

Prel. Ivan J a c k a n i n, s. 18 [proza].

2. „Revue svetovej literatúry” 2017, nr 2.

Dymińska Dominika

Mięso / Mäso [fragment powieści].

Prel. Kristína K a r a b ová, s. 69-76 [proza].

\section{Dzido Marta}

Dwie litery / Tri písmená.

Prel. Patrik O r i e š e k, s. 66-68 [proza]. 


\section{Grzegorzewska Wioletta}

[Opowiadania ze zbioru Guguty]

Filumenistka / Filumenistka, s. 32-34

Myszka / Myška, s. 30-32

Wieczornica proporczyków / Večierok s vlajočkami, s. 27-29

Zielone Świątki / Zelené sviatky, s. 29-30.

Prel. Kristína Ka r a b ová [proza].

\section{Karpowicz Ignacy}

Sońka / Sonka [fragment powieści].

Prel. Patrik O r i e š e k, s. 5-11 [proza].

\section{Keff Bożena}

Utwór o Matce i Ojczyźnie / Skladba o Matke a Vlasti

[fragment utworu].

Prel. Kristína K a r a b o vá, s. 82-87 [proza].

\section{Konstrat Bartosz}

[Wiersze z tomu Samochody i krew]

Contes Barbares / Contes Barbares, s. 98-99

Dogasov úl*, s. 96-97

Liturgia $^{*}$, s. 99

Piski / Piskot, s. 95

Prach, prášok, s. 99

Sędziowie / Sudcovia, s. 96

Skratka*, s. 97-98

Správa*, s. 97.

Prel. Patrik O ri e š ek [poezja].

\section{Macierzyński Piotr}

[Wiersze z tomu Kwik]

doma sa bolo treba správat*, s. 78

ked'sa vracal opitý rád má*, s. 79

otec mal čierny pás $v$ deptaní, s. 78-79

Predstavujem si aké by to bolo krásne $e^{\star}$, 77

rodičia museli často chodit do školy ${ }^{\star}$, s. 77

Škola písania básni ${ }^{*}$, s. 80-81

Varšava*, s. 80.

Prel. Patrik O ri e š e k [poezja]. 


\section{Murek Weronika}

[Opowiadanie ze zbioru Uprawa roślin południowych metoda

Miczurina]

Organizacja snu w przedszkolu /

Organizovanie spánku v materskej škole.

Prel. Patrik O ri e š e k, s. 35-41 [proza].

\section{Nowicka Bronka}

[Wiersze z tomu Nakarmić kamień]

Hrebeñ $^{*}$, s. 92

Kameñ $^{*}$, s. 93

Krabička*, s. 93-94

Lyžička*, s. 92-93

Mydlo*, s. 94

Pančuchy*, s. 92.

Prel. Patrik O ri eš ek [poezja].

\section{Orsz-Wolf Julia}

Wars Wojny / Vojny - Wars [fragment powieści].

Prel. Kristína K a r a b o vá, s. 100-109 [proza].

\section{Pułka Tomasz}

[Wiersze z tomu Zespół szkół]

72-FN-BH / 72-FN-BH, s. 112-113

Anekdota o filme , s. 114

Dlaczego klasycy / Prečo klasici, s. 110

Ibuprofén $n^{\star}$, s. 112

Luk*, s. $111-112$

Margarin $^{*}$, s. 110

$\mathrm{Mean}^{\star}$, s. 113-114

Ruiny ruin / Rozvaliny rozvalín, s. 113

Samsung / Samsung, s. 114

Solec Zdrój / Solec zdrój, s. 113

Tik tak*, s. 114

Trututu błyszczy trąbka / Tramtarará leskne sa trúbka, s. 113

Úbohá rekvizita tvojej predstavivosti ${ }^{\star}$, s. 110-111.

Prel. Patrik O ri e š e k [poezja].

\section{Pustkowiak Patrycja}

Nocne zwierzęta / Nočné zvieratá [fragment powieści].

Prel. Patrik O r i e š e k, s. 12-16 [proza].

\section{Sadulski Bartosz}

[Wiersze z tomu Tarapaty]

6. jún $n^{*}$ s. 88 
báseřn $^{*}$ s. 88

heavy metal ${ }^{*}$, s. $88-89$

koniec s koncom ${ }^{\star}$, s. 89

o utekani ${ }^{*}$, s. 89

prázdny priestor ${ }^{\star}$, s. 90

ravensberger $1500^{\star}$, s. 89

spoiler $^{\star}$, s. 91

tá $i z b a^{\star}$, s. 88

zúrivý máj*, s. 91

zviera $v$ stratosfére ${ }^{\star}$, s. 89-90.

Prel. Patrik O ri eš ek [poezja].

\section{Shuty Sławomir}

[Opowiadania ze zbioru Cukier w normie]

Jak Mirek został abstynentem /

Ako sa Mirek stal abstinentom, s. 47-48

Komunia / Prvé sväté prijímanie, s. 45-47

O Wandzie, co Niemca nie chciała /

O Wande, ktorá nechcela Nemca, s. 42-44

Podwójnie filtrowane / Dvojité filtrovanie, s. 44-45.

Prel. Patrik O ri eš e k [proza].

\section{Szczerek Ziemowit}

Pec Verejná: Bezpolšstie*.

Prel. Patrik O r i e š e k, s. 57-65 [proza].

\section{Wilk Paulina}

[Fragment powieści Znaki szczególne]

Pożyczone szczęście / Požičané štastie.

Prel. Kristína K a r a b o vá, s. 49—56 [proza].

\section{Witkowski Michał}

Margot / Margot [fragment powieści].

Prel. Patrik O r i e š ek, s. 17-26 [proza].

3. „Romboid” 2017, nr 5-6.

\section{Bargielska Justyna}

Żona chomika / Žena škrečka, s. 53-54

\section{Gren Roman}

$\mathrm{Krik}^{\star}$, s. $55-56$

Nikto ma nelúbi ${ }^{\star}$, s. 57-58

\section{Liskowacki Artur Daniel}

Języki obce / Cudzie jazyky, s. 59-60

Zima / Zima, s. 61.

Prel. Zuzana C o m p elová [proza]. 
4. „Slovenské pohlady” 2017, nr 2.

\section{Świderska-Pelinko Marta}

Tam gdzie łkaja skrzypce / Tam, kde plačú husle

[fragment powieści].

Prel. Radovan B re n ku s, s. 98-107 [proza].

5. „Vlna” 2017, nr 73.

Machej Zbigniew

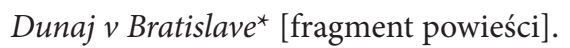

Prel. Karol C h m e 1, s. 79—90 [proza].

ZUZANA OBERTOVÁ | dr, polonistka, adiunkt w Katedrze Filologii Słowiańskich na Wydziale Filozoficznym Uniwersytetu Komeńskiego w Bratysławie. Bada polsko-słowackie stosunki literackie, XX-wieczną literaturę polską oraz jej przekłady na język słowacki. Jej zainteresowania naukowe skupiają się głównie wokół zagadnień recepcji literatury polskiej na Słowacji. 